\title{
Effects of glutamine on markers of intestinal inflammatory response and mucosal permeability in abdominal surgery patients: A meta-analysis
}

\author{
XIAO-LIANG SHU ${ }^{1}$, TING-TING YU², KAI KANG ${ }^{2}$ and JIAN ZHAO ${ }^{2}$ \\ ${ }^{1}$ Department of Nutrition, Jinshan Hospital, Fudan University School of Medicine, Shanghai 201508; \\ ${ }^{2}$ Tongji University School of Medicine, Shanghai 200092, P.R. China
}

Received November 2, 2015; Accepted July 14, 2016

DOI: $10.3892 /$ etm.2016.3799

\begin{abstract}
The present meta-analysis was carried out to determine whether supplementation with glutamine (Gln) would reduce the intestinal inflammatory response and mucosal permeability in patients undergoing abdominal surgery. The PubMed, EMBASE, Web of Science, and The Cochrane Library databases were searched for randomized controlled trials on the effects of supplementation with Gln, and published from August, 1966 to June 2014. Inclusion criteria for the meta-analysis were: i) Study design was a randomized controlled trial, ii) study included patients undergoing abdominal surgery, iii) study patients received a supplementation with Gln peptide (Ala-Gln or Gly-Gln) whereas control patients did not use any supplements, and iv) study outcomes included inflammatory markers [C-reactive protein (CRP), tumor necrosis factor- $\alpha$ (TNF- $\alpha$ ), and interleukin (IL)-6, and IL-2 receptor] and markers of intestinal permeability [lactulose/mannitol, diamine oxidase, D(-)lactic acid, and endotoxin]. Qualities of controlled trials were assessed using the Jadad score. Meta-analyses were performed with fixed- or random-effect models depending on the heterogeneity of studies. There were 21 trials meeting the inclusion criteria. The meta-analysis revealed that the levels of CRP, TNF- $\alpha$, and IL-6 in patients supplemented with Gln were significantly lower than those in control patients, whereas the levels of IL-2 receptor were increased by GIn supplementation. Gln also significantly decreased the lactulose/mannitol ratio, the levels of diamine oxidase and endotoxin, and tended to decrease the levels of cyclic D-lactic acid. In conclusion, Gln appears to effectively reduce the inflammatory response and intestinal mucosal permeability in patients after abdominal surgery.
\end{abstract}

Correspondence to: Dr Xiao-Liang Shu, Department of Nutrition, Jinshan Hospital, Fudan University School of Medicine, 1508 Longhang Road, Shanghai 201508, P.R. China

E-mail: shuxiaoliang@vip.sina.com

Key words: glutamine, abdominal surgery, inflammatory response, intestinal mucosal permeability, meta-analysis

\section{Introduction}

Surgical trauma, burns, and severe infections cause damage to the structure and function of intestinal mucosa, and facilitate intestinal bacterial translocation. This can lead to multiple organ function failure, which is potentially be life-threatening (1).

Glutamine (Gln) is a free amino acid that comprises $>50 \%$ of the body's free amino acid pool (2). Gln is a precursor for protein synthesis and is a preferential energy source for immune and mucosal cells. In addition, this amino acid is an important intermediate in many metabolic pathways (3). Animal experiments and clinical studies demonstrated that Gln increases the height of intestinal villi, reduces intestinal mucosal permeability and enhances intestinal immune function (4). In addition, it prevents bacterial translocation and contributes to maintaining the intestinal mucosal barrier (4). The effects of Gln on intestinal inflammatory response and mucosal permeability remain to be elucidated.

In the present study, we conducted a meta-analysis to evaluate the effects of Gln supplementation in patients undergoing abdominal surgery.

\section{Materials and methods}

Search strategy. A search of the PubMed (http://www.pubmed. com), EMBASE (http://www.embase.com), Web of Science (http://apps.webofknowledge.com), and The Cochrane Library (http://www.thecochranelibrary.com) databases was conducted. Specific search strategies were developed for each database, using different combinations and variations of search terms, including 'glutamine', 'Gln', 'surgery', 'surgical', 'inflammatory reaction', 'CRP', 'TNF- $\alpha$ ', 'IL-2R', 'IL-6', 'intestine permeability' 'intestinal barrier', 'lactulose/mannitol', 'DAO', 'D(-)lactic acid', 'endotoxin', and their variants.

Study selection. Inclusion criteria for the meta-analysis were: i) Study design was a randomized controlled trial, ii) study included patients undergoing abdominal surgery, iii) study patients received a supplementation with Gln peptide (Ala-Gln or Gly-Gln) whereas control patients did not use any supplements, and iv) study outcomes included inflammatory markers [C-reactive protein (CRP), tumor necrosis factor- $\alpha$ (TNF- $\alpha$ ), 
Table I. Methodological quality assessment of randomized controlled studies.

Items $\quad 0 \quad 1 \quad 2$

\begin{tabular}{llll}
\hline Randomization & $\begin{array}{l}\text { Not randomized or inappropriate } \\
\text { method of randomization }\end{array}$ & Randomized study design & $\begin{array}{l}\text { Randomization method has been } \\
\text { described and has been appropriate } \\
\text { The method of double blinding has been } \\
\text { described and has been appropriated }\end{array}$ \\
$\begin{array}{l}\text { Wouble blinding } \\
\text { Withdrawals and and or inappropriate } \\
\text { method of blinding }\end{array}$ & Follow up not described & $\begin{array}{l}\text { Description of withdrawals and } \\
\text { dropouts has been included }\end{array}$ & \\
\hline
\end{tabular}

interleukin (IL)-2R, or IL-6] and markers of intestinal permeability (lactulose/mannitol, diamine oxidase, D(-)lactic acid, and endotoxin). Exclusion criteria for the study were: i) Studies were required to be basic research or animal studies, or systematic reviews, ii) they did not include abdominal surgery patients, iii) data were not complete or original data were not presented, and iv) repeated published reports.

Data extraction. Data were extracted independently by two investigators according to the pre-specified selection criteria. Discrepancies were resolved by discussion. From each study, information on first author, publication year, sample size, patient age and gender, outcomes, 95\% confidence interval (CI), standard deviation, and P-values were extracted. Since differences in study populations and design may have caused variations, a study-quality score was assigned using the methodological quality assessment. This assessment utilized the Jadad quality evaluation scale to rank the quality of the included randomized controlled trials. Thus, studies scored 0 point if they were not randomized controlled trials (these studies were excluded). The studies ranked 1-2 points were low quality studies, whereas studies with 3-5 points were high quality studies. The studies that received 1-5 points were included in this meta-analysis (Table I).

Statistical analysis. Data were analyzed using the statistical software provided by the Cochrane Collaboration (RevMan 5.2; Baltimore, MD, USA) and presented as means \pm standard deviations. A classified variable was presented as a relative risk with 95\% CI. A summary estimate of continuous data was presented as a weighted mean difference (WMD) with $95 \%$ CI. Before calculating the standardized mean effect for the trials, statistical heterogeneity test was evaluated by using the $I^{2}$ statistic $(\alpha=0.05)$, which assessed the appropriateness of pooling individual study results. The $\mathrm{I}^{2}$ values of 25,50 and $75 \%$, respectively, corresponded to low, moderate, and high levels of heterogeneity. The meta-analysis was performed using a fixed-effects model when there was no heterogeneity of results. For heterogeneity, a random-effects model was used. Statistical significance was set at $\mathrm{P}<0.05$, and two-tailed tests were used.

\section{Results}

Study characteristics. A total of 491 papers using the specified searching strategies were identified. By screening titles, and reading the abstracts and entire papers, 21 randomized

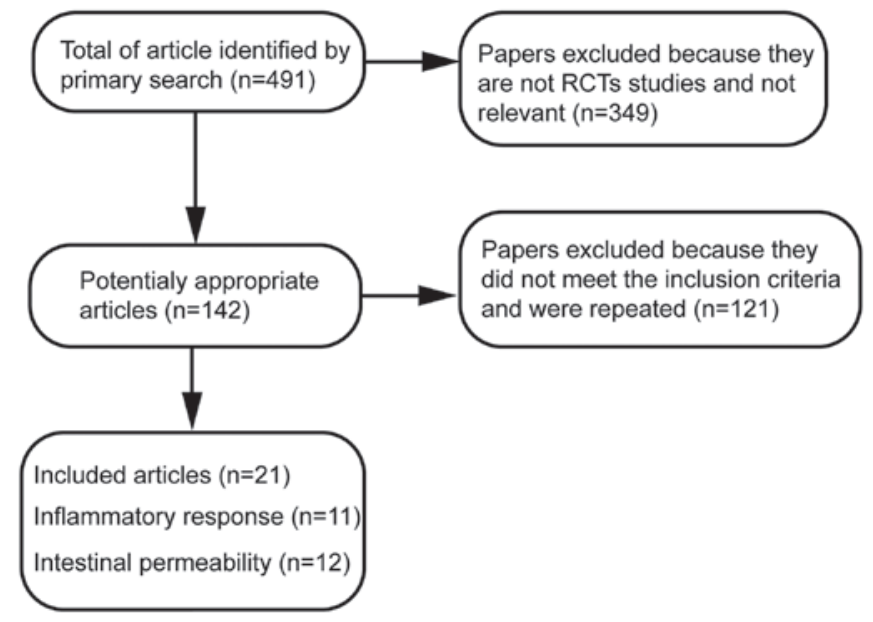

Figure 1. Flow diagram of the selection process of randomized controlled studies found in systematic search. RCT, randomized controlled trial.

controlled trials were selected (Fig. 1) (5-25). The included trials were published between August, 1966 and June 2014. Of these trials, 11 randomized controlled trials evaluated the effects of Gln on inflammatory response and 12 randomized controlled trials examined the effects of Gln on markers of intestinal permeability in abdominal surgery patients. Characteristics of randomized controlled trials included in the meta-analysis and the quality assessment of included randomized controlled trials are presented in Table II.

Inflammatory outcomes. Four studies with 182 subjects presented data on CRP levels. The data were homogeneous $\left(\chi^{2}=2.51, \mathrm{P}=0.47, \mathrm{I}^{2}=0 \%\right.$; Fig. 2$)$. Therefore, a fixed-effects model was used for analysis. The CRP levels in Gln-supplemented patients were lower than those in the control patients (WMD $=-25.40,95 \%$ CI: $-31.94,-18.85 ; \mathrm{P}<0.00001$ ).

We then identified five studies comprising 286 patients and evaluating the modulation of TNF- $\alpha$. These studies showed heterogeneity $\left(\chi^{2}=190.20, P \leq 0.00001, I^{2}=98 \%\right.$; Fig. 3). Therefore, a random-effects model was utilized. We demonstrated that patients on the Gln supplementation showed a more pronounced decrease of TNF- $\alpha$ levels compared with control patients (WMD $=-21.75,95 \%$ CI: $-32.67,-10.83 ; \mathrm{P}<0.0001$ ).

The following tested inflammatory outcome was IL-2R, which was evaluated in two studies comprising 44 patients. The fixed-effects model was used because of acceptable heterogeneity $\left(\chi^{2}=2.36, P=0.12, I^{2}=58 \%\right.$; Fig. 4). The levels of IL-2R 
Table II. RCTs included in the meta-analysis.

\begin{tabular}{|c|c|c|c|c|c|c|c|}
\hline & Sample size & Mean age & Gender (M vs. F) & & & & \\
\hline $\mathrm{RCT}$ & $\begin{array}{l}\text { Controls/ } \\
\text { glutamine- } \\
\text { supplemented }\end{array}$ & $\begin{array}{l}\text { Controls/ } \\
\text { glutamine- } \\
\text { supplemented }\end{array}$ & $\begin{array}{l}\text { Controls/ } \\
\text { glutamine- } \\
\text { supplemented }\end{array}$ & Patient type & Outcomes & $\begin{array}{c}\text { Jadad quality } \\
\text { evaluation } \\
\text { scale }\end{array}$ & Refs. \\
\hline Dong et al (2008) & $20 / 20$ & $64.2 / 66.5$ & 14 vs. $6 / 13$ vs. 7 & $\begin{array}{c}\text { Total } \\
\text { gastrectomy }\end{array}$ & CRP, TNF- $\alpha$ & 4 & (5) \\
\hline Li et al (2012) & $40 / 40$ & $58 / 57$ & 23 vs. $17 / 25$ vs. 15 & Gastric cancer & TNF- $\alpha$ and IL-6 & 4 & (6) \\
\hline Feng et al (2007) & $58 / 58$ & $56 / 56$ & & Gastric cancer & $\mathrm{TNF}-\alpha$ & 4 & (7) \\
\hline Lu et al (2011) & $25 / 25$ & $66.6 / 66.8$ & 16 vs. $9 / 18$ vs. 7 & $\begin{array}{c}\text { Gastrointestinal } \\
\text { cancer }\end{array}$ & $\begin{array}{l}\text { CRP, TNF- } \alpha, \\
\text { IL-6 }\end{array}$ & 4 & (8) \\
\hline Richard et al 2014 & $11 / 11$ & $47 / 45$ & 5 vs. $6 / 6$ vs. 5 & $\begin{array}{l}\text { Hepatic } \\
\text { resection }\end{array}$ & CRP & 4 & (9) \\
\hline Yeh et al (2008) & $35 / 35$ & $59 / 58$ & 18 vs. $17 / 20$ vs. 15 & $\begin{array}{c}\text { Gastrointestinal } \\
\text { surgery }\end{array}$ & CRP & 4 & (10) \\
\hline Xu et al (2011) & $40 / 40$ & $61.2 / 62.3$ & 21 vs. $19 / 20$ vs. 20 & Gastrectomy & $\begin{array}{c}\text { TNF- } \alpha, \\
\text { lactulose/ } \\
\text { mannitol, } \\
\text { diamine oxidase }\end{array}$ & 3 & (11) \\
\hline Yang et al (1999) & $7 / 7$ & $43 / 43$ & & Gastrectomy & IL-2R & 3 & $(12)$ \\
\hline Song et al (2002) & $20 / 20$ & $56 / 56$ & & $\begin{array}{l}\text { Colorectal } \\
\text { cancer }\end{array}$ & IL-2R & 4 & (13) \\
\hline Quan et al (2010) & $10 / 10$ & $52 / 50$ & 6 vs. $4 / 5$ vs. 5 & $\begin{array}{l}\text { Abdominal } \\
\text { surgery }\end{array}$ & $\begin{array}{l}\text { IL-6, Lactulose/ } \\
\text { mannitol, } \\
\text { diamine oxidase }\end{array}$ & 4 & (14) \\
\hline Lin et al (2005) & $23 / 25$ & $67.6 / 66.7$ & 14 vs. $9 / 14$ vs. 11 & $\begin{array}{l}\text { Abdominal } \\
\text { surgery }\end{array}$ & IL-6 & 4 & $(15)$ \\
\hline Jian et al (1999) & $30 / 30$ & $54.5 / 55.5$ & 31 vs. $29 / 35$ vs. 25 & $\begin{array}{c}\text { Gastrointestinal } \\
\text { surgery }\end{array}$ & $\begin{array}{c}\text { Lactulose/ } \\
\text { mannitol }\end{array}$ & 4 & (16) \\
\hline Quan et al (2004) & $10 / 10$ & $48.3 / 48.3$ & 7 vs. $3 / 6$ vs. 4 & $\begin{array}{l}\text { Abdominal } \\
\text { surgery }\end{array}$ & $\begin{array}{c}\text { Lactulose/ } \\
\text { mannitol, } \\
\text { diamine oxidase }\end{array}$ & 4 & (17) \\
\hline Zhu et al (2005) & $20 / 21$ & $67.6 / 68.4$ & 12 vs. $8 / 12$ vs. 9 & $\begin{array}{l}\text { Abdominal } \\
\text { secondary } \\
\text { surgery }\end{array}$ & $\begin{array}{l}\text { Lactulose/ } \\
\text { mannitol, } \\
\text { endotoxin }\end{array}$ & 4 & (18) \\
\hline Zhu et al (2000) & $15 / 15$ & $66.7 / 68.3$ & 7 vs. $8 / 6$ vs. 9 & $\begin{array}{c}\text { Gastrointestinal } \\
\text { surgery }\end{array}$ & $\begin{array}{c}\text { Lactulose/ } \\
\text { mannitol }\end{array}$ & 4 & (19) \\
\hline Zhao et al (2010) & $20 / 20$ & $61.7 / 62.5$ & 12 vs. $8 / 14$ vs. 6 & Gastric cancer & $\begin{array}{c}\text { Diamine oxidase, } \\
\text { D(-)lactic acid }\end{array}$ & 3 & $(20)$ \\
\hline Gu et al (2006) & $36 / 36$ & $61.7 / 62.5$ & 28 vs. $12 / 20$ vs. 12 & Gastric cancer & D(-)lactic acid & 3 & $(21)$ \\
\hline Niu et al (2011) & $29 / 29$ & & 15 vs. $14 / 17$ vs. 12 & $\begin{array}{l}\text { Abdominal } \\
\text { surgery }\end{array}$ & $\mathrm{D}(-)$ lactic acid & 3 & $(22)$ \\
\hline Li et al (2006) & $40 / 40$ & $57.6 / 58.2$ & 30 vs. $10 / 27$ vs. 13 & $\begin{array}{c}\text { Cardiac } \\
\text { carcinoma }\end{array}$ & Endotoxin & 4 & $(23)$ \\
\hline Yao et al (2002) & $14 / 14$ & $60.1 / 59.0$ & & $\begin{array}{l}\text { Abdominal } \\
\text { surgery }\end{array}$ & Endotoxin & 4 & $(24)$ \\
\hline Yao et al (2005) & $20 / 20$ & $57.4 / 56.1$ & & $\begin{array}{c}\text { Gastrointestinal } \\
\text { surgery }\end{array}$ & Endotoxin & 4 & $(25)$ \\
\hline
\end{tabular}

RCT, randomized controlled trial; TNF- $\alpha$, tumor necrosis factor- $\alpha$; IL, interleukin; CRP, C-reactive protein; F, female; M, male.

in patients supplemented with Gln were higher than those in control patients (WMD=4.46, 95\% CI: 2.85, 6.06; $\mathrm{P}<0.00001)$.
The final inflammatory marker analyzed was IL-6. Four studies $(n=198)$ tested the change of IL-6 levels on Gln supple- 


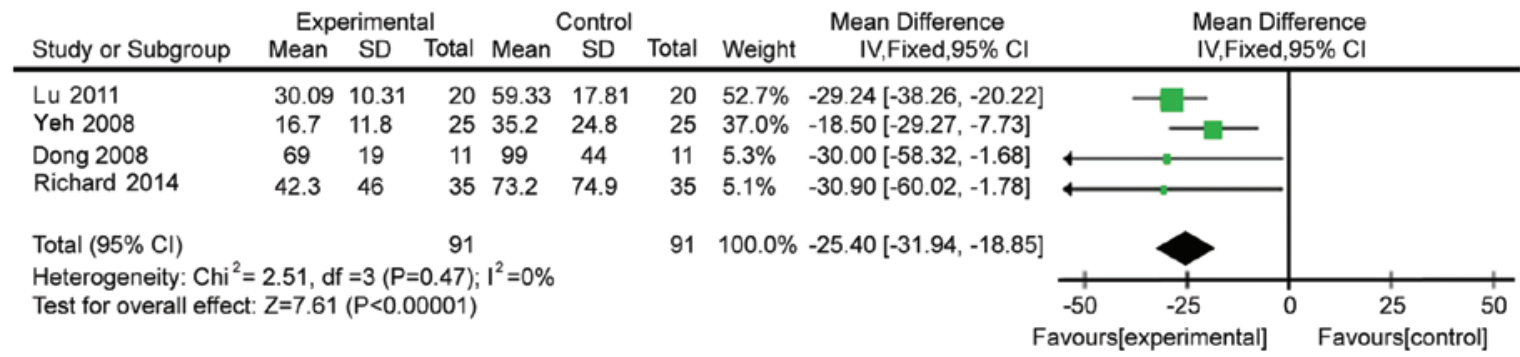

Figure 2. Forest plot of C-reactive protein levels in patients with and without supplementation with glutamine: A fixed-effects model. SD, standard deviation; $\mathrm{CI}$, confidence interval.

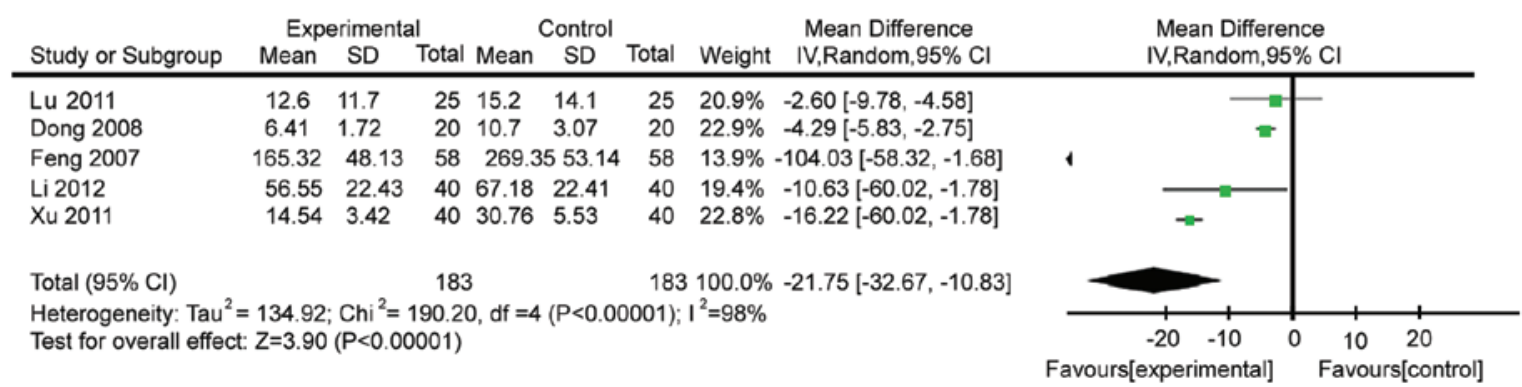

Figure 3. Forest plot of tumor necrosis factor- $\alpha$ levels in patients with and without supplementation with glutamine: A random-effects model. SD, standard deviation; CI, confidence interval.

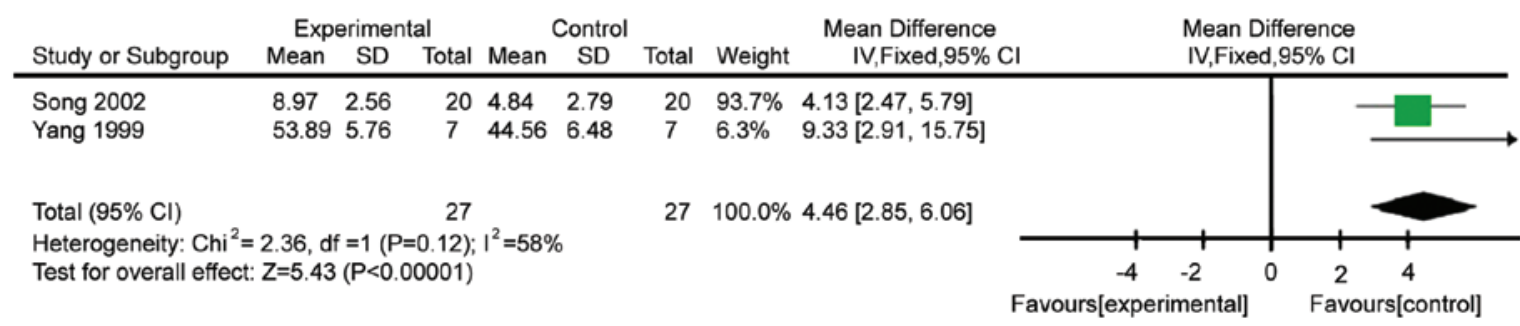

Figure 4. Forest plot of interleukin-2R levels in patients with and without supplementation with glutamine: A fixed-effects model. SD, standard deviation; CI, confidence interval.

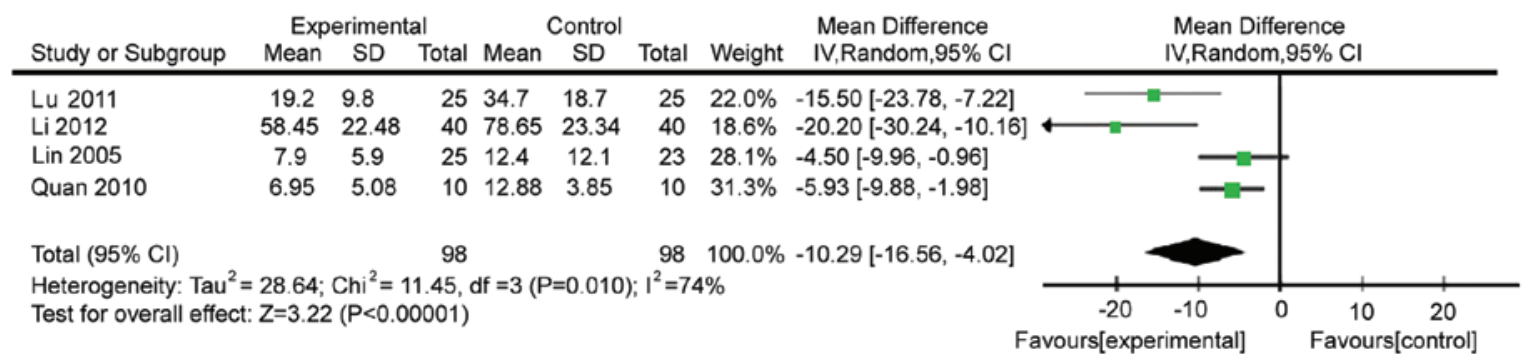

Figure 5. Forest plot of interleukin-6 levels in patients with and without supplementation with glutamine: A random-effects model. SD, standard deviation; CI, confidence interval.

mentation. These studies were heterogeneic $\left(\chi^{2}=11.45, \mathrm{P}=0.010\right.$, $\mathrm{I}^{2}=74 \%$; Fig. 5). Therefore, a random-effects model was used for analysis. IL-6 levels were significantly lower in patients supplemented with Gln (WMD=-10.29, 95\% CI: -16.56, -4.02; $\mathrm{P}=0.001$ vs. control patients). Publication bias is shown in Fig. 6 .

Evaluation of mucous membrane permeability. We analyzed the effects on the ratio of lactulose/mannitol after abdominal surgery. There were six studies comprising 251 patients that reported this ratio. These studies were heterogeneous $\left(\chi^{2}=27.86\right.$, $\mathrm{P}<0.0001, \mathrm{I}^{2}=82 \%$; Fig. 7). Heterogeneity may have been caused by different times of Gln supplementation or different doses, or by the type of disease. Thus, the random-effects model was utilized for the meta-analysis. Gln was found to significantly decrease intestinal permeability (WMD $=-0.05,95 \% \mathrm{CI}:-0.09$, $-0.01 ; \mathrm{P}=0.007$; Fig. 8). Publication bias is shown in Fig. 8 . 


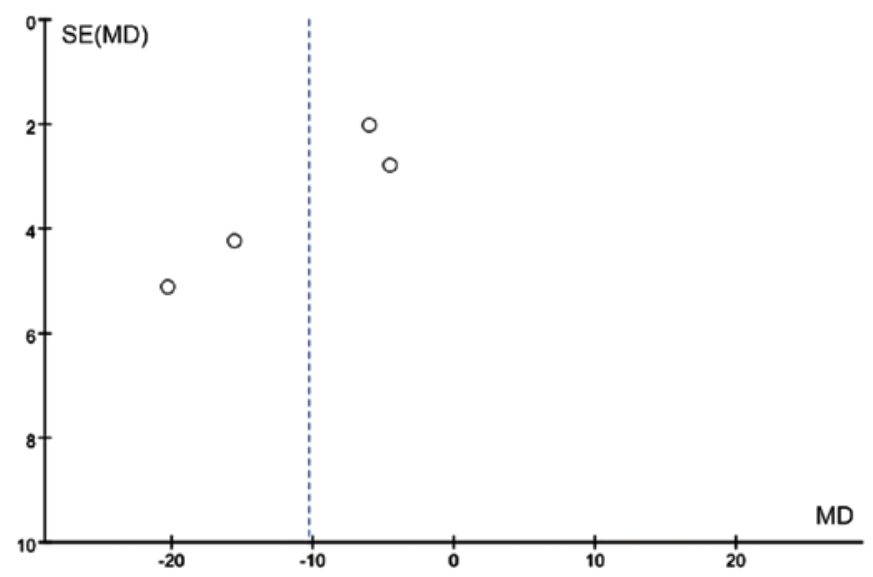

Figure 6. Funnel plot of studies reporting interleukin-6 levels in patients with and without supplementation with glutamine. SE, standard error; MD, mean difference.

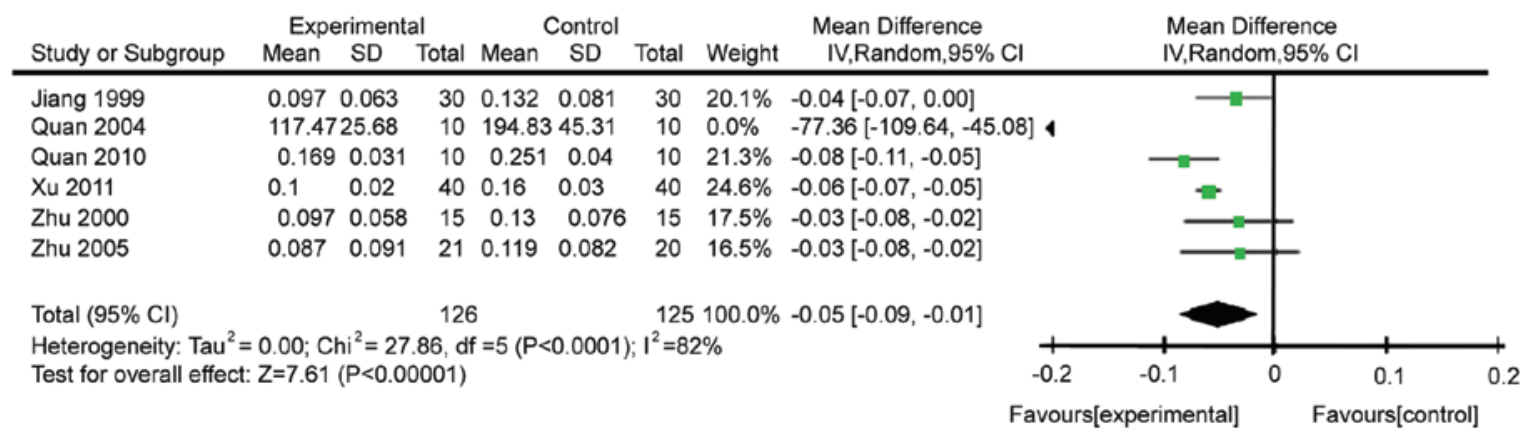

Figure 7. Forest plot of changes in lactulose/mannitol ratio in patients with and without supplementation with glutamine: A random-effects model. SD, standard deviation; $\mathrm{CI}$, confidence interval.

Modulation of the diamine oxidase levels was also analyzed. Four studies comprising 160 patients were included. The heterogeneity was acceptable $\left(\chi^{2}=3.81, \mathrm{P}=0.28, \mathrm{I}^{2}=21 \%\right)$, allowing to use the fixed effects model for meta-analysis. Gln significantly decreased the levels of diamine oxidase (WMD $=-1.60,95 \%$ CI: $-1.89,-1.31 ; \mathrm{P}<0.00001$; Fig. 9). Publication bias is shown in Fig. 10.

The effects of Gln supplementation on the levels of $\mathrm{D}(-)$ lactic acid were analyzed. Three studies $(n=160)$ reported the effects after abdominal surgery. Due to the heterogeneity of these studies $\left(\chi^{2}=134.29, \mathrm{P} \leq 0.00001, \mathrm{I}^{2}=99 \%\right)$, the random-effects model was utilized. The difference between Gln-treated and control patients did not reach statistical significance (WMD=-8.14, 95\% CI: -18.12, -1.84; $\mathrm{P}=0.11$; Fig. 11).

The effects of Gln on endotoxin levels were then analyzed. Five studies comprising 210 subjects were performed and the endotoxin levels reported. The studies were heterogeneous $\left(\chi^{2}=983.78, \mathrm{P}<0.0001, \mathrm{I}^{2}=100 \%\right)$, prompting us to use the random effects model. The results showed that Gln significantly decreases the levels of endotoxin (WMD $=-0.36$, 95\% CI: -0.45, -0.27; P<0.00001; Fig. 12).

\section{Discussion}

Gln is as an important free amino acid in the human body and is used in clinical practice as a supportive supplementation. Gln improves immune function and nutritional status,

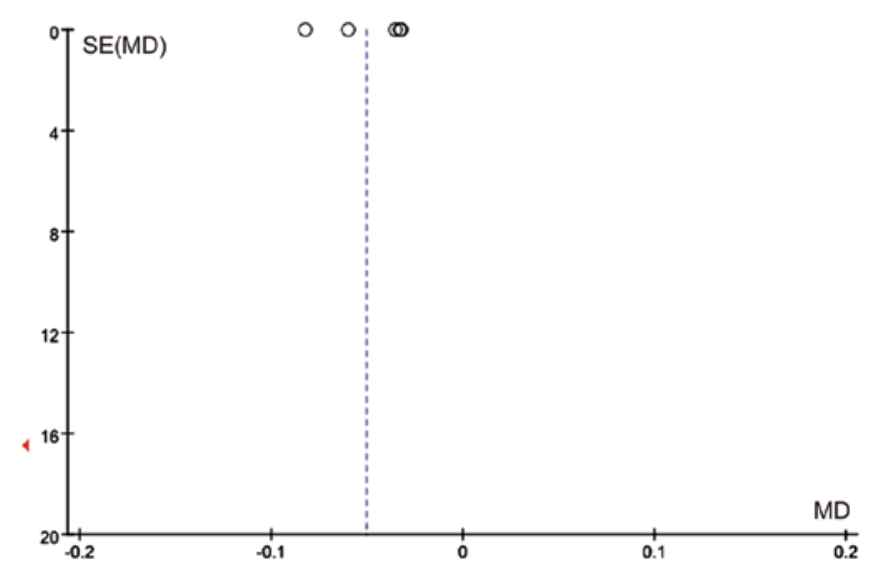

Figure 8. Funnel plot of studies reporting the change of lactulose/mannitol ratio in patients with and without supplementation with glutamine. and without supplementation with glutamine. SE, standard error; MD, mean difference.

and protects gastrointestinal mucosa. These effects promote patient recovery. Gln ameliorates the function of intestinal mucosal cells, lymphocytes, macrophages, and neutrophils (12-15). This amino acid is indispensible for intestinal mucosal epithelial cell metabolism as it improves intestinal mucosal repair and restoration of barrier function of the intestinal mucosa $(26,27)$. Thus, patients who do not receive 


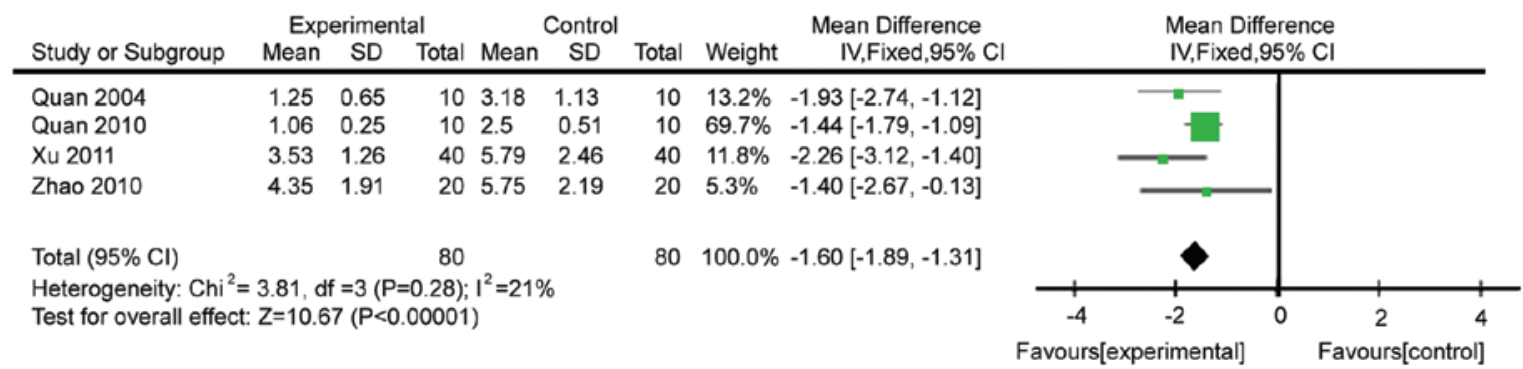

Figure 9. Forest plot of diamine oxidase levels in patients with and without supplementation with glutamine: A fixed-effects model. SD, standard deviation; CI, confidence interval.

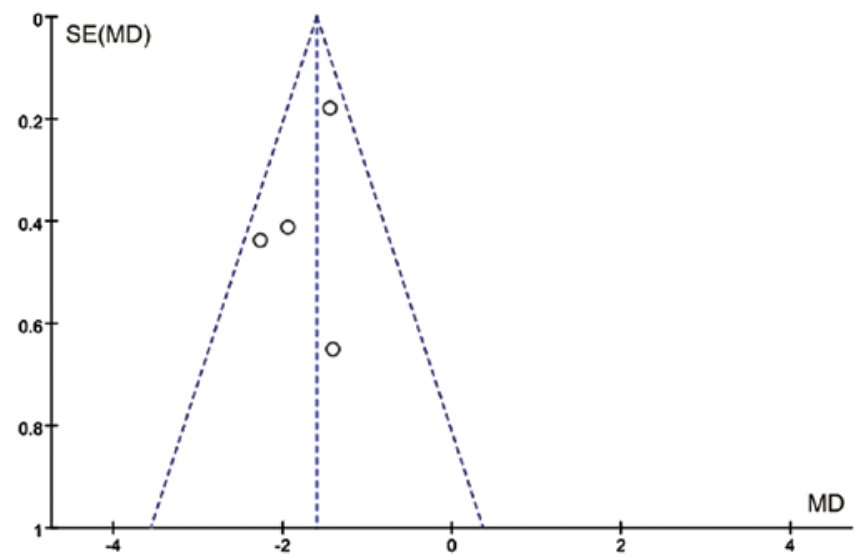

Figure 10. Funnel plot of studies reporting diamine oxidase levels in patients with and without supplementation with glutamine. SE, standard error; MD, mean difference.

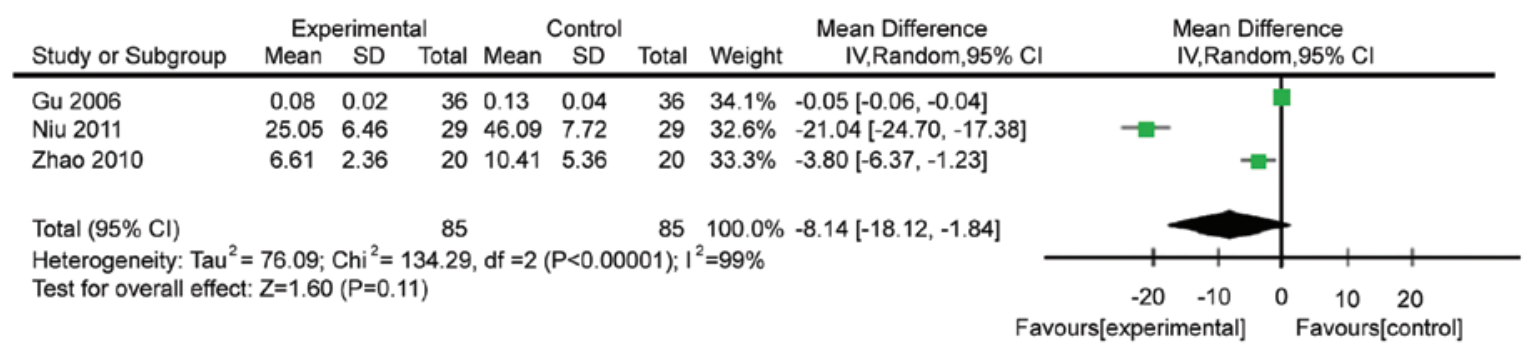

Figure 11. Forest plot of D(-)lactic acid levels in patients with and without supplementation with glutamine: A random-effects model. SD, standard deviation; CI, confidence interval.

\begin{tabular}{|c|c|c|c|c|c|c|c|c|c|c|}
\hline \multirow{2}{*}{ Study or Subgroup } & \multicolumn{3}{|c|}{ Experimental } & \multicolumn{3}{|c|}{ Control } & \multicolumn{2}{|r|}{ Mean Difference } & & $\begin{array}{l}\text { Mean Difference } \\
\text { IV,Random, } 95 \% \mathrm{Cl}\end{array}$ \\
\hline & 0.53 & 0.65 & 40 & 3.98 & 0.25 & 40 & $9.8 \%$ & $-3.45[-3.67,-3.23]$ & 4 & \\
\hline Quan 2004 & 0.18 & 0.06 & 10 & 0.25 & 0.08 & 10 & $20.9 \%$ & $-0.07[-0.13,-0.01]$ & & \\
\hline Yao 2005 & 0.049 & 0.01 & 20 & 0.051 & 0.012 & 20 & $23.2 \%$ & $-0.00[-0.01,0.00]$ & & \\
\hline Zhu 2005 & 0.05 & 0.04 & 21 & 0.06 & 0.02 & 21 & $23.0 \%$ & $-0.01[-0.03,0.01]$ & & $\mathrm{T}$ \\
\hline
\end{tabular}

Figure 12. Forest plot of endotoxin levels in patients with and without supplementation with glutamine: A random-effects model. SD, standard deviation; CI, confidence interval.

Gln supplementation demonstrate increased intestinal permeability (28).
Our study evaluated the effects of Gln on inflammatory markers CRP, TNF- $\alpha$, IL-2R, and IL- 6 in patients after 
abdominal surgery. CRP, often used as an inflammatory and disease activity marker (29), is a sensitive marker of non-specific inflammatory response. TNF- $\alpha$ is an important inflammatory mediator in trauma, infection and stress situations. IL-2R binds to IL-2, which is an important immune regulatory cytokine (30). IL-6 is an inflammatory mediator closely associated with disease outcome and prognosis. The results of the present meta-analysis show that the levels of CRP, TNF- $\alpha$, and IL- 6 were decreased by Gln supplementation, whereas the levels of IL-2R were increased.

We evaluated the effects of Gln on the markers of intestinal mucosal permeability, as demonstrated by parameters such as lactulose/mannitol ratio, and the levels of diamine oxidase, D(-) lactic acid, and endotoxin. When the intestinal mucosal barrier function is impaired, the connection between intestinal mucosal cells is disturbed and intercellular space increases, leading to an increased lactulose/mannitol ratio (31). Damaged intestinal mucosal epithelial cells release diamine oxidase, which elevated the levels of this marker in blood plasma. Therefore, diamine oxidase is a reliable plasma marker for indirect assessment of the integrity of the mucosal epithelial cell layer $(32,33)$. D(-)lactic acid is the metabolite of bacterial fermentation. When intestinal mucous membrane permeability increases, higher levels of $\mathrm{D}(-)$ lactic acid reach the bloodstream (34). Thus, monitoring of $\mathrm{D}(-)$ lactic acid levels in blood can reflect intestinal mucosal damage and impaired permeability. Endotoxin is a virulence factor produced by gram-negative bacteria. Under normal circumstances, intact intestinal barrier prevents endotoxin from entering the blood circulation (33). When the intestinal barrier is damaged, endotoxin levels in peripheral blood increase. Our analyses show that the lactulose/mannitol ratio, and the levels of diamine oxidase and endotoxin were significantly lower in patients supplemented with Gln. This result indicates that Gln can decrease intestinal mucosal permeability in patients after abdominal surgery and restore the intestinal mucosal barrier function.

This meta-analysis also has certain limitations. First, this study included 21 studies, with higher proportion of studies from China and lower proportion of international studies. This constituted a possible selection bias. Second, whereas all the studies included in the meta-analysis utilized a randomized and parallel study design, they were not always blinded. Third, because of insufficient sample size, publication bias may be large. For example, since there were only three published reports on $\mathrm{D}(-)$ lactic acid, heterogeneity and publication bias was sizable.

In conclusion, Gln appears to effectively reduce the inflammatory response and intestinal mucosal permeability in patients after abdominal surgery.

\section{Acknowledgements}

The present study was supported by the 'Twelfth Five-Year' National Key Technology R\&D Program of China (grant no. 2012BAI35B03).

\section{References}

1. Fink MP and Delude RL: Epithelial barrier dysfunction: A unifying theme to explain the pathogenesis of multiple organ dysfunction at the cellular level. Crit Care Clin 21: 177-196, 2005.
2. Marik PE: Maximizing efficacy from parenteral nutrition in critical care: Appropriate patient populations, supplemental parenteral nutrition, glucose control, parenteral glutamine, and alternative fat sources. Curr Gastroenterol Rep 9: 345-353, 2007.

3. Morlion BJ, Stehle P, Wachtler P, Siedhoff HP, Köller M, König W, Fürst P and Puchstein C: Total parenteral nutrition with glutamine dipeptide after major abdominal surgery: A randomized, double-blind, controlled study. Ann Surg 227: 302-308, 1998.

4. Jiang ZM and Yu JK: Gutbarrierdysfunction and parenteral/enteral nutrition update. Med Res Bul 29: 2-5, 2000 (In Chinese).

5. Dong GL, Kang ZH, Liu XN, Ji G, Wang CY, Wang Y, Liu DH and Wang WZ: Effect of alanyl-glutamine on the clinical outcome of patients after gastrectomy. Chin J Clin Nutr 16: 70-73, 2008 (In Chinese).

6. Li XH, Yi SY, Zhao J and Rou RL: Effects of preoperative glutamine-supplemented enteral nutrition support on immunity and inflammatory response in patients with gastric cancer following radical operation. Front Med 3: 121-122, 2012 (In Chinese).

7. Feng MH, Xiong B, Chen JK, Xue XB, Wu ZQ, Yang GL, Wang $\mathrm{F}$ and $\mathrm{Hu} \mathrm{MB}$. Glutamine enhances heat shock protein 70 and attenuates tumor necrosis factor- $\alpha$ release in neoplastic patients after operation. Chin J Exp Surg 24: 1589-1590, 2007 (In Chinese).

8. Lu CY, Shih YL, Sun LC, Chuang JF, Ma CJ, Chen FM, Wu DC, Hsieh JS and Wang JY: The inflammatory modulation effect of glutamine-enriched total parenteral nutrition in postoperative gastrointestinal cancer patients. Am Surg 77: 59-64, 2011.

9. Richard V, Dahiya D, Kaman L, Raj P and Behera A: Effect of perioperative glutamine administration on $\mathrm{C}$-reactive protein and liver function tests in patients undergoing hepatic resection. Pol Przegl Chir 86: 11-16, 2014.

10. Yeh CN, Lee HL, Liu YY, Chiang KC, Hwang TL, Jan YY and Chen MF: The role of parenteral glutamine supplement for surgical patient perioperatively: Result of a single center, prospective and controlled study. Langenbecks Arch Surg 393: 849-855, 2008.

11. Xu XD, Sun YS, Shao QS, Hu JF, Qian ZY, Zhou YL and Ye ZY: Effect of early enteral nutrition supplemented with glutamine on postoperative intestinal mucosal barrier function in patients with gastric carcinoma. Zhonghua Wei Chang Wai Ke Za Zhi 14: 436-439, 2011 (In Chinese).

12. Yang JT, Wang ZG and Zhu PF: Effect of glutamine supplementation on cellular immunity in surgical patients. Chin J Exp Surg 16: 124-126, 1999 (In Chinese).

13. Song JX, Qing SH, Huang XC and Qi DL: Clinical importance of glutamine-supplemented parenteral nutrition in patients with colorectal cancer. Chin J Clin Nutr 10: 165-168, 2002 (In Chinese).

14. Quan ZF, Yuan ZC and Li JS: Effects of alanyl-glutamine dipeptide administration on postoperative intestinal permeability and systemic inflammatory response. Parenter Enter Nutr 17: 13-16, 2010 (In Chinese).

15. Lin MT, Kung SP, Yeh SL, Liaw KY, Wang MY, Kuo ML, Lee PH and Chen WJ: Glutamine-supplemented total parenteral nutrition attenuates plasma interleukin- 6 in surgical patients with lower disease severity. World J Gastroenterol 11: 6197-6201, 2005.

16. Jian ZM, Cao JD, Zhu XG, Zhao WX, Yu JC, Ma EL, Wang XR, Zhu MW, Shu H and Liu YW: The impact of alanyl-glutamine on clinical safety, nitrogen balance, intestinal permeability, and clinical outcome in postoperative patients: A randomized, double-blind, controlled study of 120 patients. JPEN J Parenter Enteral Nutr 23 (Suppl 5): S62-S66, 1999.

17. Quan ZF, Yang C, Li N and Li JS: Effect of glutamine on change in early postoperative intestinal permeability and its relation to systemic inflammatory response. World J Gastroenterol 10: 1992-1994, 2004

18. Zhu MW, Tang DN, Wei JM, Zhao X, Ye GD, Long HK and Cao JD: Effects of glutamine dipeptide on plasma endotoxin, outcome and health economy of elderly post-abdominal operation patients. Chin J Geriatr. 24: 585-588, 2005 (In Chinese).

19. Zhu M, Tang D, Zhao X, Cao J, Wei J, Chen Y, Xiao L and Sun Q: Impact of glutamine of gut permeability and clinical prognosis on the aging patients undergoing gastric-intestinal operation. Zhongguo Yi Xue Ke Xue Yuan Xue Bao 22: 425-427, 2000 (In Chinese).

20. Zhao XL, He XD, Cui Q, Deng ZY and Yang Y: Effects of glutamine on intestinal barrier function in patients undergoing postoperative chemotherapy for gastric cancer. Chinese Journal of General Surgery 4: 132-134, 2010 (In Chinese). 
21. Gu YH, Ca H, Li YP and Yi Y: Effects of glutamine on patients undergoing postoperative chemotherapy for gastric cancer. Chin J Clin Nutr 14: 369-373, 2006 (In Chinese).

22. Niu ZJ, Zhang XF, Zhao CL, Liu T and Zhai ET: Value of glutamine in conservative treatment of patients with intestinal obstruction after abdominal operation. World Chin J Digestology 19: 3714-3718, 2011 (In Chinese).

23. Li JM, Lai DN and He XL: Support of ala-glutamine-enriched parenteral nutrition on radical resection of cardiac carcinoma patients. Journal of Abdominal Surgery 19: 226-228, 2006 (In Chinese).

24. Yao GX, Jiang ZM, Wang XR, Ma EL, Yang NF and Zhao YP: Role of perioperative glutamine-dipeptide supplementation on plasma endotoxin level, plasma endotoxin inactivation capacity, and clinical outcome. Chin J Clin Nutr 10: 19-23, 2002 (In Chinese).

25. Yao GX, Xue XB, Jiang ZM, Yang NF and Wilmore DW: Effects of perioperative parenteral glutamine-dipeptide supplementation on plasma endotoxin level, plasma endotoxin inactivation capacity and clinical outcome. Clin Nutr 24: 510-515, 2005.

26. dos Santos R, Viana ML, Generoso SV, Arantes RE, Davisson Correia MI and Cardoso VN: Glutamine supplementation decreases intestinal permeability and preserves gut mucosa integrity in an experimental mouse model. JPEN J Parenter Enteral Nutr 34: 408-413, 2010.

27. Wu GH, Wang H, Zhang YW, Wu ZH and Wu ZG: Glutamine supplemented parenteral nutrition prevents intestinal ischemiareperfusion injury in rats. World J Gastroenterol 10: 2592-2594, 2004.
28. van der Hulst RR, van Kreel BK, von Meyenfeldt MF, Brummer RJ, Arends JW, Deutz NE and Soeters PB: Glutamine and the preservation of gut integrity. Lancet 341: 1363-1365, 1993.

29. Sablotzki A, Börgermann J, Baulig W, Friedrich I, Spillner J, Silber RE and Czeslick E: Lipopolysaccharide-binding protein (LBP) and markers of acute-phase response in patients with multiple organ dysfunction syndrome (MODS) following open heart surgery. Thorac Cardiovasc Surg 49: 273-278, 2001

30. Taniguchi T and Minami Y: The IL-2/IL-2 receptor system: A current overview. Cell 73: 5-8, 1993.

31. Kubica P, Kot-Wasik A, Wasik A, Namieśnik J and Landowski P: Modern approach for determination of lactulose, mannitol and sucrose in human urine using HPLC-MS/MS for the studies of intestinal and upper digestive tract permeability. J Chromatogr B Analyt Technol Biomed Life Sci 907: 34-40, 2012.

32. Luk GD, Bayless TM and Baylin SB: Diamine oxidase (histaminase). A circulating marker for rat intestinal mucosal maturation and integrity. J Clin Invest 66: 66-70, 1980

33. Ferrier L, Bérard F, Debrauwer L, Chabo C, Langella P, Buéno L and Fioramonti J: Impairment of the intestinal barrier by ethanol involves enteric microflora and mast cell activation in rodents. Am J Pathol 168: 1148-1154, 2006.

34. Lin J, Nafday SM, Chauvin SN, Magid MS, Pabbatireddy S, Holzman IR and Babyatsky MW: Variable effects of short chain fatty acids and lactic acid in inducing intestinal mucosal injury in newborn rats. J Pediatr Gastroenterol Nutr 35: 545-550, 2002. 